\title{
OPTICAL PROPERTIES OF HgMgMnTe CRYSTALS
}

\author{
V.M. Frasunyak, M.P. Gavaleshko and I.G. OrletskiI \\ Department of Physical Electronics, State University \\ 2 Kotsubinsky str., Chernivtsi, 274012, Ukraine
}

\begin{abstract}
Optical properties of new semimagnetic semiconductors of $\mathrm{Hg}_{1-x-y} \mathrm{Mg}_{x} \mathrm{Mn}_{y} \mathrm{Te}(x<0.10, y<0.10)$ in the fundamental absorption region at $T=290 \mathrm{~K}$ and $80 \mathrm{~K}$ were investigated. A shift of absorption band edge was revealed when composition and temperature changed. The energy gap and its temperature coefficient were evaluated as well as analytical expressions which describe $E_{\mathrm{g}}(x, y, T)$ for quaternary solid solutions were analysed.
\end{abstract}

PACS numbers: 75.50.Pp, 78.20.Dj, 78.30.Fs

\section{Introduction}

Solid solutions based on the mercury chalcogenides are optimal materials for the devices which work in the infrared region. However, because of instability of material, difficulties appear in fabricating and exploitation of these devices. One of the possible ways to solve this problem is to search more stable ternary or quaternary materials, including the introduction of magnetic component into the diamagnetic matrix of $\mathrm{HgTe}$.

\section{Experimental technique}

The research results of the optical properties of new semimagnetic quaternary solid solutions of $\mathrm{Hg}_{1-x-y} \mathrm{Mg}_{x} \mathrm{Mn}_{y} \mathrm{Te}(x<0.10, y<0.10)$ are presented.

The $\mathrm{HgMgMnTe}$ alloys were received by joint melting of high pure components $(\mathrm{Hg}-99.9999, \mathrm{Te}-99.9999, \mathrm{Mg}-99.99, \mathrm{Mn}-99.99)$ in quartz thick-wall containers inside which there was pirolytical carbon covering. Temperature conditions of synthesis were chosen experimentally, determined from the phase state diagrams for the according ternary systems $[1,2]$. The alloy crystallization was hold by means of Bridgman method with velocity of $1 \mathrm{~mm} /$ hour under the temperature gradient equal to $30 \mathrm{grad} / \mathrm{cm}$ on the crystallization front. X-ray and metallographic analysis confirmed the only phase of the obtained crystals.

For solid solutions based on mercury chalcogenides the component segregation along the ingot length is inherent, and this creates some difficulties in selection 
of the samples of required composition content. When $\mathrm{Mn}$ in the lattice of diamagnetic crystal distributes statistically its concentration can be determined by the paramagnetic value of magnetic susceptibility $\kappa$. The measurement results showed that in $80-290 \mathrm{~K}$ interval $\kappa_{\mathrm{Mn}}$ in $\mathrm{HgMgMnTe}$ is well described by Curie-Weiss law

$$
\kappa_{\mathrm{Mn}}=\frac{y N \mu_{\mathrm{ef}}^{2}}{3 k_{0} M_{0}(T-\theta)},
$$

where $y-M n$ concentration, $N$ - Avogadro number, $M_{0}$ - molecular mass of the crystal, $\mu_{\mathrm{ef}}$ - effective magnetic moment of $\mathrm{Mn}$ ion, $\theta$ - Curie temperature, $k_{0}$ - Boltzmann constant. In the crystals of given symmetry the $\mathrm{Mn}$ content and its distribution in the crystals (data in Table) were estimated experimentally. $\mathrm{Mg}$ content in samples was evaluated from the results of density. On the basis of experimentally determined density dependencies of $\rho$ for $\mathrm{MgHgTe}$ and $\mathrm{MnHgTe}$, $\rho(x, y)$ for $\mathrm{HgMgMnTe}$ was obtained according to [3], which can be presented in such a way

$$
\rho(x, y)=8.08-4.285 x-3.222 y .
$$

Knowing the concentration and sample density, $\mathrm{Mn}$ content of crystal was simply determined by means of Eq. (2).

The samples prepared for the measurements were annealed additionally $(T=500 \mathrm{~K})$ in $\mathrm{Hg}$ vapours for $250-300$ hours. This allowed to decrease the concentration of charge carriers and not to consider the shift of absorption edge due to Burstein-Moss effect, which appears in degenerated semiconductors, and to evaluate the energy gap with higher accuracy. When levels of filling are small the parabolic zones approach can be used which allows to use the theory of absorption edge in square dispersion law approach for electrons and holes [4].

TABLE

Parameters of $\mathrm{HgMgMnTe}$ crystals.

\begin{tabular}{c|c|c|c|c|c|c|c|c|c}
\hline \hline$N$ & $x$ & $y$ & $\begin{array}{c}\kappa \cdot 10^{6}, \\
290 \mathrm{~K} \\
\mathrm{~cm}^{3} / \mathrm{g}\end{array}$ & $\begin{array}{c}\rho \\
\mathrm{g} / \mathrm{cm}^{3}\end{array}$ & $\begin{array}{c}E_{\mathrm{g}} \\
290 \mathrm{~K} \\
\mathrm{eV} \\
{[5]}\end{array}$ & $\begin{array}{c}E_{\mathrm{g}} \\
80 \mathrm{~K} \\
\mathrm{eV} \\
{[5]}\end{array}$ & $\begin{array}{c}E_{\mathrm{g}} \\
\mathrm{exp} . \\
290 \mathrm{~K} \\
\mathrm{eV}\end{array}$ & $\begin{array}{c}E_{\mathrm{g}} \\
\mathrm{exp} . \\
80 \mathrm{~K} \\
\mathrm{eV}\end{array}$ & $\begin{array}{c}\mathrm{d} E_{\mathrm{g}} / \mathrm{d} T \\
\times 10^{4} \\
\mathrm{eV} / \mathrm{K}\end{array}$ \\
\hline 1 & 0.068 & 0.020 & 0.65 & 7.72 & 0.157 & 0.083 & 0.14 & 0.09 & 2.38 \\
2 & 0.071 & 0.049 & 1.70 & 7.62 & 0.253 & 0.196 & 0.22 & 0.17 & 2.14 \\
3 & 0.070 & 0.061 & 2.12 & 7.58 & 0.286 & 0.231 & 0.26 & 0.23 & 1.9 \\
4 & 0.072 & 0.097 & 3.45 & 7.46 & 0.415 & 0.369 & 0.40 & 0.37 & 1.43 \\
5 & 0.093 & 0.031 & 0.95 & 7.58 & 0.272 & 0.218 & 0.25 & 0.20 & 2.1 \\
6 & 0.08 & 0.067 & 2.52 & 7.52 & 0.346 & 0.296 & 0.31 & 0.27 & 1.8 \\
7 & 0.094 & 0.082 & 3.25 & 7.41 & 0.441 & 0.397 & 0.39 & 0.37 & 1.76
\end{tabular}




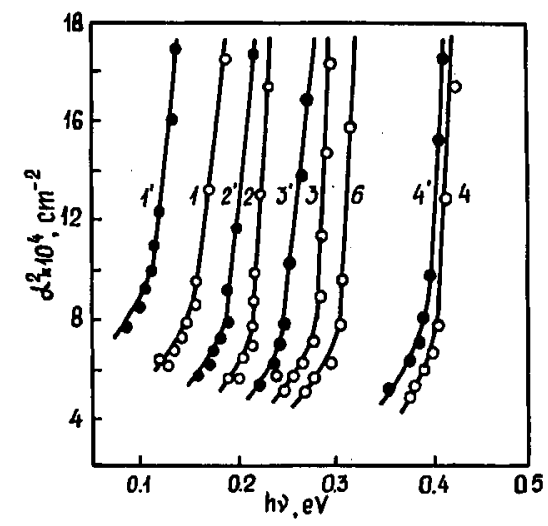

Fig. 1. Spectral distribution of $\alpha^{2}=f(h \nu)$ for $\mathrm{Hg}_{1-x-y} \mathrm{Mg}_{x} \mathrm{Mn}_{y}$ Te crystals (denotions in Table). $-80 \mathrm{~K}, \circ-290 \mathrm{~K}$.

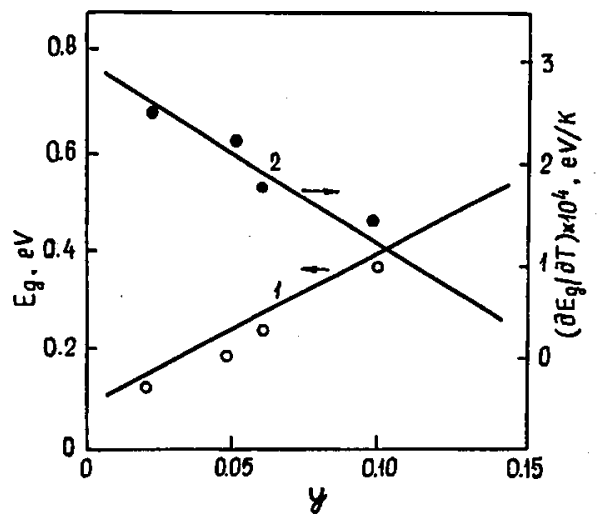

Fig. 2. Energy gap $E_{\mathrm{g}}$ and temperature coefficient $\beta=\mathrm{d} E_{\mathrm{g}} / \mathrm{d} T$ dependencies on $\mathrm{Mn}$ content for $\mathrm{Hg}_{1-x-y} \mathrm{Mg}_{x} \mathrm{Mn}_{y} \mathrm{Te}(x=0.07), T=290 \mathrm{~K} .1,2$ - calculated data [5], o- experimental results.

In Fig. 1 the experimental results of spectral dependence $\alpha^{2}(h \nu)$ in the fundamental absorption is shown for samples of $\mathrm{Hg}_{1-x-y} \mathrm{Mg}_{x} \mathrm{Mn}_{y} \mathrm{Te}$ at 80 and $290 \mathrm{~K}$. At these temperatures for all values of $y$ absorption spectra are analogous, $\alpha^{2}(h \nu)$-curves have the exponential form, characteristic of the most of $\mathrm{A}^{2} \mathrm{~B}^{6}$ semiconductors. Sharp growing of absorption coefficient from one hand characterises the satisfactory homogeneity of the samples under investigation and, from the other hand, the participation of direct transitions in the formation of absorption edge.

As $\mathrm{Mn}$ content increases in $\mathrm{Hg}_{1-x-y} \mathrm{Mg}_{x} \mathrm{Mn}_{y} \mathrm{Te}$ fundamental absorption edge moves to higher energies, e.g. the energy gap increases. Evaluated values of $E_{\mathrm{g}}$ for $\mathrm{HgMgMnTe}$ are presented in Table and in Fig. 2.

When temperature decreases fundamental absorption edge shifts to the long- 
-wave region of the spectrum (curves 1-4, Fig. 1). By the value of temperature shift of the fundamental absorption, temperature coefficient of the energy gap change $\left(\beta=\mathrm{d} E / \mathrm{d} T_{\mathrm{g}}\right)$ was determined (Table). When concentration of $\mathrm{Mn}$ in the crystals increases the value of $\beta$ decreases. Such a dependence is observed for solid solutions with inverted energy structure.

The energy gap of the quaternary solid solution can be described by analytical expressions using corresponding values of the initial compounds $[3,5,6]$. The best approach of experimental and calculated data when expression (3) from [5] is used

$$
E_{\mathrm{g}}(x, y)=(1-x-y) E_{\mathrm{g}}(\mathrm{HgTe})+x E_{\mathrm{g}}(\mathrm{MgTe})+y E_{\mathrm{g}}(\mathrm{MnT} \mathrm{e}) .
$$

Thus in $\mathrm{HgTe}-\mathrm{MgTe}-\mathrm{MnTe}$ system there exist solid solutions whose properties can be changed and further investigation of them will show their competition ability comparing with another solid solutions of mercury chalcogenides.

\section{References}

[1] M.P. Gavaleshko, P.M. Gorley, S.Yu. Paranchich, V.M. Frasunjak, V.V. Khomjak, Izv. Akad. Nauk SSSR Neorg. Mater. 19, 328 (1983).

[2] R.T. Delves, B. Lewis, J. Phys. Chem. Solids 24, 549 (1963).

[3] W.V. Anderson, Infrared Phys. 20, 363 (1980).

[4] J. Pankov, Opticheskije processy v poluprovodnikach, Mir, Moskva 1973 (in Russian).

[5] J.K. Furdina, J. Appl. Phys. 64, 29 (1988).

[6] S. Takejama, S. Narita, J. Appl. Phys. 24, 1270 (1985). 